\title{
Negros Contando (e Fazendo) sua História: Alguns Significados da Trajetória da Companhia Negra de Revistas (1926) ${ }^{1}$
}

Tiago de Melo Gomes

\section{Resumo}

No segundo semestre de 1926 formou-se a Companhia Negra de Revistas, reunindo músicos e artistas de renome no Rio de Janeiro e em São Paulo. A trajetória da companhia surge como sendo de grande utilidade para os historiadores interessados na consolidação de uma auto-imagem do Brasil que privilegia os aspectos "mestiços" da nação. Primeiramente, a trajetória da companhia mostra a participação de negros como agentes de sua presença como símbolos nacionais, pois as peças da companhia valorizavam a cultura negra como cultura nacional, operação que tem sido apontada como atividade meramente de intelectuais brancos. Além disto, mostra ainda o lado transnacional desta valorização da cultura negra ocorrida nos anos 1920. Isto se dá quando se tem em mente que no mesmo período a (s) cultura(s) negra $(\mathrm{s})$ fazia $(\mathrm{m})$ grande sucesso em Paris, e negros norte-americanos se exibiam por todo o período para o público brasileiro como membros de companhias de teatro francês. A Companhia Negra de Revistas se mostra assim como um excelente ponto de partida para se repensar uma variedade de questóes sobre etnicidade, nacionalidade, influências culturais transnacionais, participação popular na formação de um "caráter nacional", cidadania, entre outras.

Palavras-chave: identidade nacional, teatro de revista, massificação cultural, relações raciais, cidadania. 
Tiago de Melo Gomes

\begin{abstract}
Negroes Telling (and Making) their History: Some Meaningful Highlights of the Companhia Negra de Revistas (1926)

The Companhia Negra de Revistas was founded in the second half of 1926, and included renowned musicians and artists in Rio de Janeiro and São Paulo. The trajectory of the company is of major importance to historians interested in consolidating an image of Brazil that stresses the "mestizo" aspects of the nation. In the first place, it shows the participation of Negroes and is an instrument for acknowledging them as a national symbol since the shows produced by the company valorized black culture as a national culture, as against considering it an activity performed only by white intellectuals. Secondly, it also shows the transnational aspect of valorizing Negro culture in the 1920s. Proof of this is that during that same period Negro culture(s) enjoyed great success in Paris, and Afro-Americans gave shows throughout those years to the Brazilian public as members of French theater companies. The Companhia Negra de Revistas is thus an excellent starting point for rethinking a number of questions on ethnics, nationality, transnational cultural influences, popular participation in founding a "national theater", citizenship, and so forth.
\end{abstract}

Keywords: national identity; Companhia Negra de Revistas; mass culture; racial relationships; citizenship.

\title{
Résumé
}

Des Noirs qui Racontent (et qui font) leur Histoire: Quelques Significations de la Trajectoire de la Companhia Negra de Revistas (1926)

Pendant le deuxième semestre de 1926, s'est formée la Companhia Negra de Revistas, réunissant des musiciens et artistes fameux de Rio de Janeiro et de São Paulo. Le parcours de cette compagnie peut servir d'exemple aux historiens intéressés de tracer une image de soi du Brésil privilégiant les aspects de ses métissages. Tout d'abord, cette trajectoire montre la participation des Noirs en tant qu'agents d'une présence noire et comme symboles nationaux, puisque les pièces jouées par la compagnie promeuvent la culture noire au Brésil, où souvent la culture n'est vue que comme une affaire de Blancs. Ensuite, elle montre aussi le côté transnational de la valorisation de la culture noire survenue dans les années 1920. À l'époque, les cultures noires connaissaient un grand

Estudos Afro-Asiáticos, Ano 23, no 1, 2001, pp. 54-83 
Negros Contando (e Fazendo) sua História...

succès à Paris, des noirs nord-américains jouant sur les scènes brésiliennes comme acteurs de théâtre français. La Companhia Negra de Revistas est donc un excellent point de départ pour une révision des questions concernant l'ethnicité, la nationalité, les influences culturelles transnationales, la participation populaire dans la formation d'un "caractère national" et de la citoyenneté, entre autres.

Mots-clé: identité nationale; théâtre de variétés; massification culturelle; relations raciales; citoyenneté 
$\mathrm{C}$ onforme tem sido apontado à exaustão por uma extensa bibliografia especializada, as décadas de 1920 e 1930 representaram momentos decisivos na formulação e consolidação da imagem do Brasil como uma democracia racial, em que o fato de o país ser caracterizado pela miscigenação, não sendo apenas amplamente reconhecido, também se apresentava como motivo de orgulho (cf., p. ex., Fry, 1982; DaMatta, 1990; Ortiz, 1994; Mota, 1994; Skidmore, 1989; Schwarcz, 1995; Vianna, 1995, Dantas, 1988). Neste contexto, o samba, a mulata, a feijoada, o "estilo brasileiro de jogar futebol”, a malandragem, entre outros símbolos, passam, a partir deste período, a ser reconhecidos por toda uma nação como elementos centrais na definição de sua auto-imagem. Graças a uma grande quantidade de trabalhos desenvolvidos em áreas como história das idéias e crítica literária, alguns aspectos do processo de formação e positivação desta auto-imagem brasileira estão já bem claros, em especial a atuação de alguns intelectuais, sendo Gilberto Freyre e Mário de Andrade dois dos exemplos mais marcantes.

Em meio ao processo acima citado, surgiu, em meados de 1926, uma companhia de teatro que apresentava como peculiaridade a negritude de todos os seus membros. A Companhia Negra de Revistas, que reunia artistas negros de renome - como os músicos Pixinguinha, Bonfiglio de Oliveira, Sebastião Cirino e De Chocolat - obteve grande sucesso em todo o segundo semestre daquele ano no Rio de Janeiro e em São Paulo, dissolvendo-se no início de 1927, já bastante enfraquecida por divergências internas. Sua peça de maior sucesso, que permaneceu por um período mais longo em cartaz, Tudo Preto (de autoria de De Chocolat, o fundador da companhia), era caracterizada justamente por debater intensamente os temas mais caros à constituição da identidade nacional naquele momento. Mestiçagem, influências negras na cultura brasileira, racismo, influências regionais diferenciadas em um caráter nacional único, todas questôes caras a intelectuais como Gilberto Freyre, eram debatidas por uma companhia negra

Estudos Afro-Asiáticos, Ano 23, no 1, 2001, pp. 56-83 
Negros Contando (e Fazendo) sua História...

de teatro perante um público tão amplo quanto internamente diferenciado, seja em termos étnicos, como no aspecto socioeconômico.

Em pleno auge dos debates sobre identidade nacional, mestiçagem e temas afins, como um grupo de negros abordaria tais questôes? Que lições o conhecimento desta abordagem da companhia pôde trazer ao enorme conhecimento deste processo já tão estudado anteriormente?

Neste contexto, o objetivo central deste artigo é o de estudar, a partir do surgimento da Companhia Negra de Revistas, desde alguns aspectos de sua trajetória e de sua recepção, à possível participação de amplos segmentos da população no debate acerca da identidade nacional nos anos 20. Desta forma, ao formularem-se estas questóes, a finalidade não é apreender, de forma pseudo-objetiva, o que os negros, como um todo, pensavam a respeito do intenso debate que se desenvolvia naquele momento. $\mathrm{O}$ objetivo seria, antes, exemplificar, através de um grupo de negros que não se encaixa nos limites da história intelectual ou literária tradicional, como pessoas que nunca foram intelectuais, políticos ou membros de grupos de elite podem ter participado ativamente da construção de uma identidade nacional "mestiçac". Assim, se quer demonstrar que a tradicional caracterização das atividades negras deste período como meramente "culturais" e "apolíticas" peca por procurar a "política" apenas em movimentos organizados de massa, deixando de notar o tom claramente político de algumas destas manifestações culturais.

O objetivo central deste texto está inteiramente conectado a uma segunda questão: a da importância do processo de massificação cultural no Rio de Janeiro, no período. A cultura de massas é aqui pensada não apenas como veiculadora de idéias que são produzidas totalmente fora de seu domínio, mas sim como importante fórum de debate. Não se pretende, aqui, debater a natureza e a função do consumo massificado na sociedade capitalista, ou pensar a massificação cultural de forma despolitizada, apenas como elemento democratizador da cultura. Neste texto, o termo "cultura de massas" indica, antes, o propósito de descrever a ampliação das possibilidades de veiculação de produtos culturais.

Com isto, pretende-se abordar a diversidade de facetas assumidas pelo processo de reavaliação da "cultura popular" nesse período, de acordo com o contexto estudado. Este é um assunto ao qual tem sido dedicado pouco espaço, com idéias que, formuladas em locais diversos, com finalidades variadas, têm sido freqüente-

Estudos Afro-Asiáticos, Ano 23, no 1, 2001, pp. 57-83 
mente generalizadas para todo o país. Assim, textos de Gilberto Freyre sobre o Nordeste, ou dos modernistas paulistas sobre seu estado, são transformados em explicação para todo o movimento de revalorização do "nacional" e do "popular" ocorrido em escala nacional. Contudo, esta reavaliação foi revestida de peculiaridades em cada região, bastando notar a importância, neste processo de construção de símbolos identitários, da cultura negra urbana no Rio de Janeiro e do cotidiano rural entre paulistas e gaúchos, por exemplo. A reavaliação que levou uma cultura negra a uma posição central na definição da identidade carioca, em parte a mesma cultura temida e desprezada poucos anos antes, permanece como um ponto obscuro da história do Rio de Janeiro. Por que na Capital Federal estes símbolos provenientes da cultura negra urbana, e não qualquer outro tipo de "cultura popular", ocuparam papel tão importante na formação da identidade da cidade? Através de que meios se deu este processo de reavaliação?

Tendo em vista as questóes colocadas, pretende-se conceber este debate sobre identidades de forma a não colocar intelectuais e políticos fora da sociedade, tentando pensar os mesmos em interação com seu contexto sociocultural. Talvez seja possível argumentar que alguns grupos específicos (modernistas paulistas, regionalistas pernambucanos e políticos estadonovistas etc.) tenham, de fato, ocupado uma posição de grande importância na consolidação da identidade mestiça da nação. Mas estes personagens certamente tiveram suas concepções influenciadas por sua inserção em uma sociedade de massas, no mínimo no nível da necessidade de compreender o material disponível para veiculação da ideologia desejada. Tornou-se lugar comum, por exemplo, apontar a música de Ari Barroso (principalmente as exaltações regionais e nacionais) como prestação de serviço à ideologia de Getulio Vargas. Caso isto seja verdade, o que se tem esquecido de observar é que estes gêneros não foram inventados por Ari Barroso a soldo de Vargas: tais ritmos estavam disponíveis no meio do entretenimento de massas há muito tempo, e certamente por isto foram aproveitados pelo Estado Novo.

A identificação de Vargas com o malandro carioca no teatro de revista do período do Estado Novo (identificação que o ditador soube capitalizar), pode ser citada como mais um claro momento em que altos escalóes da política nacional buscam seu intento ideológico utilizando o arsenal cultural disponibilizado pela cultura de massas. Note-se que não se trata de mera apropriação, para fins político-ideológicos, de idéias apolíticas e inocentes circulan-

Estudos Afro-Asiáticos, Ano 23, no 1, 2001, pp. 58-83 
Negros Contando (e Fazendo) sua História...

tes no meio cultural; o malandro e o samba-exaltação eram elementos centrais em um importante debate que se desenrolava, nos meios de comunicação de massa, a respeito do tema da identidade nacional, pelo menos desde a década de 1920 (Gomes, 1998). Assim, o que se pretende aqui não é negar a possibilidade de que alguns intelectuais, políticos e membros da elite possam ter desempenhado papel destacado na definição da identidade nacional; seria desejável, antes, apontar o fato de que os debates promovidos nestes círculos não estavam isolados de discussóes semelhantes que ocorriam em um âmbito mais amplo.

A utilização de uma companhia de teatro de revista como fonte para o acompanhamento de idéias circulantes no Rio de Janeiro na primeira metade do século se deve às peculiaridades deste gênero teatral. Em primeiro lugar, era marcado, fundamentalmente, pela utilização do debate sobre fatos da atualidade em suas peças, ao lado da exploração da música popular, do humor malicioso. Em segundo lugar, é uma forma de arte inteiramente inserida na dinâmica da cultura de massas: as peças chegavam a ser apresentadas em três sessôes diárias, e quando uma peça começava a perder público, saía de cena. Com isso, muitas vezes as peças entravam e saíam de cartaz com grande velocidade. Bastante significativa, a este respeito, é a definição, corrente na época, segundo a qual, quando o bolo de dinheiro proveniente da arrecadação de uma peça diminuía dois dedos, era a hora de mudar o repertório. Em terceiro lugar, como decorrência de sua inserção na produção cultural massiva, o teatro de revista via-se obrigado a recrutar seu público entre as camadas mais variadas da sociedade. Nesse contexto, a platéia era bastante diversificada, tendo em vista a grande variedade de preços cobrados para se assistir a uma mesma peça. ${ }^{2}$

Reunindo as características aqui enumeradas, tem-se um gênero do entretenimento de massas que debatia os fatos mais comentados do momento perante uma platéia diversificada, com a permanente necessidade de sucesso. Neste quadro, o intuito de produzir peças bem-sucedidas em termos de público era alcançado através da recorrência de temas centrais no debate da época, dentro dos quais poderiam ser atribuídos sentidos variados por uma platéia bastante heterogênea. ${ }^{3}$ Se a entrada mais barata para um espetáculo de teatro musicado podia ser comprada pelo valor equivalente ao de um exemplar de jornal, é de se esperar que parte do público fosse recrutado entre uma população que não possuía alto poder aquisitivo. Por outro lado, o preço muitas vezes maior de

Estudos Afro-Asiáticos, Ano 23, no 1, 2001, pp. 59-83 
uma frisa ou camarote indica que uma peça de sucesso deveria dar conta desta variedade de público.

Sendo o debate sobre o caráter nacional um tema recorrente nos palcos da revista carioca, a exaltação do caráter mestiço da nação, nesse contexto, deveria estar balizada pela necessidade de agradar a todos. Neste sentido, o resultado era uma clara predominância de ambientes "populares" nos palcos da revista carioca, que invariavelmente tinha quadros passados em morros, subúrbios e bairros de forte presença negra, como Saúde e Cidade Nova. Os tipos eram aqueles que ainda hoje aparecem como característicos destes espaços: malandros, mulatas, portugueses, policiais, caipiras recém-chegados, valentões, entre outros. Estes personagens, em especial o malandro e a mulata, serviam como personificação do país.

Contudo, isto não significa que, ao assistir a uma peça em que malandros e mulatas representavam um alegre, festivo e mestiço caráter da nação, todos os espectadores tenham voltado para suas casas convencidos de que esta associação seria plenamente verdadeira, ficando orgulhosos com esta constatação. Isto seria negar a possibilidade de autonomia do consumo massificado. A produção cultural de massas, como nota Michel de Certeau, é necessariamente reinterpretada pelos consumidores. A dificuldade, no estudo deste fenômeno, reside no fato de que esta produção "não deixa aos 'consumidores' um lugar para marcar o que fazem com os produtos" (Certeau, 1998:39). O fato de estes tipos consagrados surgirem como símbolos nacionais não apenas nas peças do período, mas em inúmeras outras fontes, com inegável recorrência até os dias de hoje, não impede que este repertório comum de símbolos permita interpretações múltiplas. Uma peça deste gênero poderia apenas divertir espectadores que conhecessem dezenas de malandros e mulatas de carne e osso, e que identificariam nos personagens da peça caricaturas divertidas de seus vizinhos e conhecidos. Outros espectadores, eventualmente dotados de preconceitos raciais, poderiam, mesmo concordando com o caráter "típico" de tais personagens, ter uma postura crítica sobre sua importância na cultura brasileira, concordando com o quadro desenhado, mas deplorando tal situação. Cenas deste tipo poderiam ainda reforçar ou desmentir crenças desenvolvidas anteriormente pelos espectadores sobre o caráter nacional.

Há, certamente, outras possibilidades de leitura, mas o que se pretende sugerir é que debates sobre temas como caráter nacional e mestiçagem estavam em discussão em um ambiente muito

Estudos Afro-Asiáticos, Ano 23, no 1, 2001, pp. 60-83 
Negros Contando (e Fazendo) sua História...

mais amplo do que em apenas alguns seletos círculos intelectuais. A reavaliação da idéia de Brasil não foi obra de poucos: estava sendo debatida em um ambiente típico da cultura de massas, como o teatro de revista. Obviamente, desta idéia, desenvolvida em dezenas de peças do período, poderiam ser extraídos os mais variados sentidos. A concordância sobre o caráter "mestiço" da nação poderia gerar simpatia, revolta, ou mero divertimento para o público do teatro de revista dos anos 1920. Mas não se pode negar a presença deste debate em um nível mais amplo que o tradicionalmente apontado pela bibliografia.

Neste contexto, a trajetória da Companhia Negra de Revistas, no segundo semestre de 1926, salta aos olhos como objeto singular para um estudo do período. Esta companhia, fundada por Jaime Silva, cenógrafo português, e pelo compositor De Chocolat, fazia questão de ressaltar o caráter negro de seus componentes a partir de seu próprio nome, assim como da denominação de sua primeira e mais importante peça: Tudo Preto, de autoria de De Chocolat. Em alguns meses de duração, a companhia obteve grande sucesso no Rio de Janeiro e em São Paulo, sublinhando a relação entre cultura negra e caráter nacional. Neste contexto, compreender a recepção dessa companhia entre o público configura-se como uma excelente janela para o entendimento de alguns sentidos do debate sobre identidades nacionais e raciais nas duas maiores cidades brasileiras nos anos 1920, inclusive por permitir ao estudioso sondar a possibilidade de recepções diferenciadas nas duas cidades.

As poucas linhas dedicadas ao assunto na bibliografia sobre teatro de revista e música popular não são de muita valia nesta tarefa, uma vez que tendem a ressaltar alguns comentários preconceituosos da imprensa da época, indicando que a Companhia teria triunfado brilhantemente apenas devido a seu mérito, vencendo os preconceitos de toda uma sociedade. Contudo, os indícios disponíveis sugerem uma situação mais ambígua. Em primeiro lugar, não haveria porque existir tamanho estranhamento com a presença de negros no palco, visto que os artistas da Companhia Negra de Revistas, inclusive os principais, já eram conhecidos do público há tempos, devido às suas atuações em outras companhias. No próprio ano de 1926, a Companhia de Burletas e Revistas do Teatro São José, grande paradigma do teatro musicado naquele momen-

Estudos Afro-Asiáticos, Ano 23, no 1, 2001, pp. 61-83 
to, ostentava 36 girls (nova denominação das coristas), ao lado de outras dez, que eram denominadas especificamente de black-girls (Nunes, 1956, v. 3:44). Sendo esta uma seção das companhias voltada basicamente para atrair a platéia masculina ao teatro através do apelo feminino, pode-se notar que a presença de mulheres negras em um palco não era vista como repulsiva à maioria dos espectadores. Os músicos, como Bonfiglio de Oliveira, Pixinguinha e Sebastião Cirino já desfrutavam de ampla reputação no meio cultural do período. Em 1922 e 1923, os cariocas haviam acorrido em massa ao Teatro Lírico, para assistir à companhia francesa $\mathrm{Ba}-\mathrm{Ta}$-Clan, que incluía diversos artistas negros norte-americanos em sua Revista Negra. Tal fato deixou impressóes duradouras:

\begin{abstract}
'A Revista Negra' e suas extravagâncias. Um espetáculo do Século XX ultracivilizado. Esses artistas já trabalharam, há dois anos, em nosso Teatro Lírico, fazendo parte da Companhia 'Ba-Ta-Clan' [em uma foto, dois artistas negros] [...]. Imagine-se uma revista, representada por atores negros e vestidos de cores berrantes, com uma orquestra de manicômio no cenário, a tocar 'one-step', acompanhado de um vozerio infernal, entre decorações estilizadas que oferecem perspectivas de 'arranha-céus' vistas por olhos de bêbado, ou cabanas tropicais à luz de uma lua absurda; acrescentem a isso muitas contorções de macaco, desnudezes de ébano maquilhadas, caricaturalmente, um canto nostálgico de emigrante, todos os contrastes, todas as incoerências...e não se terá ainda feito uma idéia exata.

Mas a gente ri e aplaude; os artistas riem; todo o mundo ri... Século XX, Paris, ultracivilização. Porque não se trata de um aspecto selvagem, segundo poder-se-ia supor e segundo dão a entender reclames hiperbólicos. 'A Revista Negra' possui requintes sutis e sua selvageria passou pelo cadinho colonizador, falando inglês; os comediantes que tomam parte nela reduzem-se a uns indivíduos corretos, de pele escura, que ensaiam conscienciosamente seus números; seus atavios extravagantes estão de acordo com a mais moderna estética; o conjunto possui uma coesão, uma coesão adrede desarticulada, tal como a arte 'futurista', a 'troupe', o cenário, os instrumentos filarmônicos, enfim, vêm de Nova York, cidade do progresso mecânico e palpável... ("O Teatro em Paris", A Notícia, 8/1/1926).
\end{abstract}

Toda a complexidade advinda da forte presença de elementos culturais identificados aos negros no cenário da massificação cultural emerge nesta matéria. $O$ primeiro parágrafo conecta, claramente, a manifestação descrita à barbárie, recorrendo a associações já bastante conhecidas. Contudo, o segundo parágrafo do texto complexifica sensivelmente o cenário, indicando (ainda que com uma ponta de ironia) a associação destas manifestações com a modernidade: "Século XX, Paris, ultracivilização". Emerge, en-

Estudos Afro-Asiáticos, Ano 23, no 1, 2001, pp. 62-83 
Negros Contando (e Fazendo) sua História...

tão, de modo claro, a ambigüidade com que foi recebida a intensificação da presença, na cultura de massas, de elementos então identificados à cultura negra. De um lado, tem-se a inspiração parisiense, já que uma companhia francesa de revistas, como era a Ba-Ta-Clan, teria apresentado ao público carioca um novo modismo existente na França: o sucesso de produtos culturais associados aos negros, sucesso este que incluía de estátuas africanas ao jazz, passando pela dançarina norte-americana Josephine Baker (Sevcenko, 1992:277-99). Por outro lado, se isto pudesse soar, na França, como mero apelo ao exótico, no Brasil, um país que há tempos procurava resolver a questão racial, e onde negros não eram estrangeiros, mas conterrâneos muitas vezes temidos ou desprezados, a questão adquiriu um outro sentido. Por um lado, a influência francesa permitia a criação de uma atmosfera mais favorável a um aumento da difusão de elementos culturais negros. Mas, por outro lado, esta novidade se chocava com idéias recorrentes de inferioridade racial. Conciliar esta rejeição com uma nova postura, mais receptiva (ou pelo menos condescendente), não parecia ser tarefa fácil para o público de elite. Contudo, a percepção de que havia, na própria Capital Federal, um grande repertório desta cultura negra agora valorizada em Paris, certamente contribuiu para formar uma atmosfera mais favorável à associação entre cultura negra e caráter nacional, fornecida pela Companhia Negra de Revistas.

Ainda que este fenômeno comportasse uma grande variedade de sentidos, muitas vezes ambíguos, parece claro o estabelecimento, no Brasil dos anos 1920, sob a influência parisiense, de um redimensionamento da cultura negra, ainda que, para muitos, sob a marca do exótico. Pode-se notar a complexidade destas associações entre cosmopolitismo, modernidade, e busca das raízes nacionais no âmbito do entretenimento massificado no programa de uma festa de revéillon no Teatro Lírico:

Danças e Canções, no 1: Extra, pela notável soprano lírico Sra. Inez Mendez (da Companhia Lírica Italiana); no 2: clássica — danças egípcias, pela distinta senhorita Mercedes Moratilia; no 3: Caracteristic Dances and Songs. Brasil: a) Abigail Maia, a Rainha da Canção Brasileira no seu repertório. b) Otília Amorim e Pedro Dias, em um número sensacional de maxixe. c) Margot e Milton, em um cateretê nortista, de sua original criação. Parte Internacional — divesos artistas apresentando vários países: França, Itália, Inglaterra, Espanha, Síria, Holanda e Portugal. no 4: Modern Dances — bailado argentino por La Norma e Wanda di Leo. Danças Norte-Americanas e Valsa Boston, figurada pelo professor Má-

Estudos Afro-Asiáticos, Ano 23, no 1, 2001, pp. 63-83 
Tiago de Melo Gomes

rio Fontes e Miss Florence Elliot. Danças Beduínas e Cantos do Deserto, conduzidos pelo professor Raschid Safadi.

Representação da peça de costumes brasileiros de Artur Azevedo, Uma Véspera de Reis na Bahia. Grande comparsaria, rancho autêntico de pastorinhas, com mise-en-scéne de Eduardo Pereira. Batalha de confete e serpentinas. Grande orquestra, com regência de Rafael Romano. No hall, um quarteto de clarins e a excelente banda de música do trio de guerra 245" (Palcos e Telas, 1/1/1920).

A programação montada pelo empresário José Loureiro, para comemorar a passagem de 1919 para 1920, é bastante útil por vários motivos. Primeiro, torna virtualmente insustentável a tradicional compartimentalização construída entre "cultura de elite" e "cultura popular" para este período. O programa contempla praticamente todos os gostos possíveis, a preços igualmente variados: frisas, 40 mil-réis; camarotes, 35 mil; poltronas, 6 mil; varandas, 6 mil; cadeiras, 4 mil; balcões, 4 mil; galerias numeradas, 2,5 mil; galerias sem número, 2 mil. A distância do preço mais caro para o mais barato, e o número de opções intermediárias, permite supor uma audiência bastante variada, assistindo a um programa que tinha de tudo um pouco. Abria com um espetáculo legitimado pelos padrões eruditos - uma soprano lírica italiana - para seguir com o exotismo de uma "dança egípcia", e chegar a uma parte de "characteristic dances and songs". Esta tinha início com três danças representando o Brasil, incluindo um maxixe e um cateretê, uma dança oriunda da cultura de massas urbana, e outra simbolizando o fascínio da cultura rural. Após as danças que representavam outros países, entravam as " modern dances", representadas pelos Estados Unidos, que aparentemente ocupavam, no imaginário do lazer massificado no Brasil, o mesmo papel que lhes foi atribuído na França: o de simbolizar a modernidade e o cosmopolitismo através de seus ritmos bastante adequados à dança. ${ }^{4}$ Após isto, entrava em cena um espetáculo que recorria a um repertório de símbolos bastante diverso: as "Danças Beduínas e Cantos do Deserto, conduzidos pelo professor Raschid Safadi”, que, com seu exotismo, tinham muito do imaginário circense, buscando, através de seus espetáculos e melodramas, levar o espectador para lugares distantes.

Após isto, vinham peças leves, apresentação de um "rancho de pastorinhas", trazendo a inevitável referência carnavalesca das festas de revéillon, e a música, igualmente diversificada, dividida em uma orquestra, um quarteto de clarins e uma banda militar, típico reduto de boa parte dos chorões cariocas. Tem-se, aqui, um programa que retrata, de modo transparente, alguns elementos

Estudos Afro-Asiáticos, Ano 23, no 1, 2001, pp. 64-83 
Negros Contando (e Fazendo) sua História...

centrais da massificação cultural dos anos do pós-guerra, em especial no que tange ao entretenimento. As referências cosmopolitas, que traziam um forte apelo "moderno" (basta lembrar as "modern dances") vinham invariavelmente intercaladas com atrações "típicas" ou mesmo exóticas, sem que se tivesse de optar por uma coisa ou outra. Os dois aspectos, o moderno-cosmopolita e o típico-exótico não devem ser vistos como competidores ou contraditórios, e sim como uma expressão particular da modernidade no contexto da massificação cultural do pós-guerra. Neste contexto, localizar as raízes da nacionalidade na cultura popular não parecia ser visto como menos moderno que dançar jazz ou freqüentar um café dançante. ${ }^{6}$ A construção realizada por historiadores e cientistas sociais para os anos 1920, como um período marcado, de um lado, por uma exibição afetada de uma cultura de elite afrancesada, e, de outro, por uma cultura popular reprimida, não parece ter sido compartilhada pelos cidadãos comuns do pós-guerra, que se divertiam com a soprano lírico Ignez Mendez, mas também com o rancho de pastorinhas, passando pelas danças beduínas do professor Raschid. Não parecia haver necessidade de escolha entre o charleston americano, a valsa francesa e o choro nacional. Estes componentes da modernidade carioca do pós-guerra misturavam-se diariamente nos palcos da Capital Federal.

Neste contexto, é possível situar o aparecimento da Companhia Negra de Revistas, que demonstrava, em primeiro lugar, um inegável tino comercial. Afinal, se a mestiçagem era exaltada no teatro de revista, perante um grupo de espectadores que ia assistir a uma "revista negra", encenada por franceses, por que não tentar um fenômeno semelhante com material nacional? Neste sentido, não é sem importância o fato de que a preparação e a estréia da companhia ocorreram no exato momento em que a Ba-Ta-Clan se exibia no Teatro Lírico, na Capital Federal, o que certamente serviu como encorajamento para a formação da Companhia Negra de Revistas. O próprio De Chocolat certamente sabia o que estava fazendo ao montar a Companhia Negra de Revistas. Afinal, era um cançonetista com duas décadas de experiência no entretenimento de massas, tendo tido, inclusive, a oportunidade de ver, com seus próprios olhos, o sucesso, na Paris do pós-guerra, de elementos da cultura negra. Provavelmente, tenha pensado em explorar, na Capital Federal de 1926, uma demanda que havia percebido, na Paris

Estudos Afro-Asiáticos, Ano 23, no 1, 2001, pp. 65-83 
de 1919, por cultura negra, e em especial por espetáculos com muita música e dança. Em breve, o sucesso de Tudo Preto mostraria que este raciocínio estava correto.

Dentro do pequeno espaço dedicado a Tudo Preto na bibliografia, comumente encontra-se uma narrativa na qual o heroísmo negro vencia o preconceito racial. Aparentemente, esta tendência nasceu com o crítico teatral Mário Nunes, em um livro, 40 Anos de Teatro, publicado em 1956, que é a fonte principal para muitos estudos sobre teatro, e que em teoria reúne suas críticas escritas entre os anos de 1913 e 1934 . No livro, encontra-se a seguinte referência a Tudo Preto: "Duas vezes repleto por um público que queria divertir-se com o grotesco e o ridículo. Enganou-se: assistiu a espetáculo normal, deveras interessante". Contudo, aqui se verifica a construção, por parte do crítico, de uma memória histórica para este evento, pois sua crítica original, publicada no Jornal do Brasil, enfatiza aspectos diferentes da peça. Em meio a uma longa e elogiosa resenha de Tudo Preto, o crítico comentava:

Certo o numeroso público que afluiu ao teatro cuidava de divertir-se com o ridículo e o grotesco de tão estranho elenco, mas depressa se convenceu de que ia assistir a um espetáculo interessante, pela maneira correta por que ia ele se desenrolando, com alguns ditos de espírito da comperage, números de canto e dança bem executados e marcados, e até mesmo revelação de pendores artísticos que deixavam a melhor das impressões" (Jornal do Brasil, 1/8/1926).

Entretanto, é duvidoso o fato de que se deva levar a sério tal afirmação a respeito de uma predisposição do público a achar a peça grotesca. Após enfileirar elogios à peça, o crítico torna a comentar tal possibilidade: "Se houve quem fosse, ontem, ao Rialto, pensando que ia ter larga oportunidade de chacotear, muito outro teria sido o ânimo com que saiu."

Aqui a situação muda bastante: Mário Nunes refere-se apenas à hipótese de alguém, e não o público como um todo, ter comparecido com a intenção de se divertir com o grotesco da peça. E mesmo assim, o tom da afirmativa sugere tratar-se mais de uma peça de retórica do que a convicção de que tal fato tenha efetivamente se dado. Com efeito, outros críticos fizeram coro com Mário Nunes, e elogiaram bastante a peça. No Jornal do Commercio, o respeitado crítico João Luso comentava a peça:

Apresentou-se ontem ao público a Companhia Negra organizada pelos Srs. Jaime Silva e Chocolate. [...]

Estudos Afro-Asiáticos, Ano 23, no 1, 2001, pp. 66-83 
Negros Contando (e Fazendo) sua História...

\begin{abstract}
A troupe mostrou-se bem ensaiada, disciplinada. Com o timbre especial da raça, há vozes interessantes; e os coros, com a orquestra ardorosamente dirigida pelo Sr. Pixinguinha, são de agradável efeito.

Entre os artistas, distinguiram-se as Sras. Jandira Aimoré, Djanira Flora, Dalva Espíndola, Rosa Negra e a barbadiana Miss Mons - que se exibiu numa curiosa dança africana, trajada de pele vermelha - e os Srs. Chocolat, Mingote, Viana e Flores.

Tudo Preto tem lindos cenários de todas as cores e da lavra do Sr. Jaime Silva.

A sala do Rialto estava absolutamente cheia, fazendo parte da assistência, segundo nos informaram, parentes de todos os artistas — L." (Jornal do Commercio, 1/8/1926)
\end{abstract}

Confirmando a boa recepção da estréia, a peça fez grande sucesso: estreando a 31 de julho de 1926, permanece em cartaz até $1^{\circ}$ de setembro (uma permanência longa em cartaz, para os padróes da revista), substituída por Preto e Branco, de Waldomiro di Roma, para voltar três dias depois e ficar em cartaz até o dia 19 do mesmo mês, quando a Companhia sai em excursão a São Paulo. Após um período na capital paulista, a companhia se dissolve, aparentemente por divergências internas. Com este quadro, não parece se confirmar a presença de um preconceito violento, generalizado e arraigado em todos os setores do público: pelo contrário, a peça parece ter agradado a muitos. Gilberto Freyre esteve presente à peça, assim como o presidente de São Paulo, Carlos de Campos. A imprensa negra paulistana não deixou de aludir ao fenômeno como um triunfo do negro brasileiro. ${ }^{7}$ Em São Paulo, a companhia liderada por De Chocolat obtém destaque na grande imprensa, e Tudo Preto recebe uma crítica extremamente favorável, dando ao teatro de revista carioca um espaço poucas vezes visto na capital paulista. ${ }^{8}$

Se essa recepção à iniciativa da Companhia Negra de Revistas indica a possibilidade de que um tipo de caracterização dos negros fosse algo muitas vezes encarado de forma positiva no ambiente do entretenimento massificado do Rio de Janeiro dos anos 1920, o conteúdo da peça em muito contribui para reforçar esta impressão. Do início ao fim do texto, De Chocolat parece empenhado em apontar a importância do caráter negro e da harmonia racial no caráter nacional. A peça é aberta com um coro de mulheres negras, que, despertando a admiração dos personagens Patrício e Benedito, os leva a decidir fundar uma companhia só com "gente da raça" para mostrar a "nossa brasilidade", já que havia um empreendimento semelhante em Paris. É possível imaginar que esta referência a Paris, logo na primeira cena, tivesse sobre muitos especta-

Estudos Afro-Asiáticos, Ano 23, no 1, 2001, pp. 67-83 
dores o efeito de afastar qualquer suspeita de que a peça promovesse o confronto racial, pois remetia ao tranquilizador e já citado sucesso da cultura negra na Paris do pós-guerra. A associação dos negros com a brasilidade também era um elemento forte, não apenas nesta peça, mas que aparecia em diversos meios e momentos no contexto cultural dos anos 1920. Sintomaticamente, na mesma cena Benedito afirma que "o preto é quem está na moda. O próprio branco brasileiro, despido de preconceitos, reconhece isto e nos adora”. Aqui é explicitada a idéia de uma convivência pacífica entre brancos e negros, idéia esta que posteriormente será associada por muitos à noção de dominação ideológica de uma elite branca sobre negros excluídos. Os próprios homens negros "de verdadeiro valor", que são citados na peça, ajudam a confirmar esta concepção: "Henrique Dias, Cruz e Sousa, André Rebouças, José do Patrocínio, Luís Gama, entre outros". Basta lembrar que, nos cânones da história oficial, Henrique Dias foi o negro que, junto com o índio Filipe Camarão e o branco André Vidal de Negreiros, teria liderado a expulsão dos holandeses de Pernambuco em 1654, em um episódio recorrente para exaltar a idéia das três raças fundadoras de uma nacionalidade mestiça.

Após isto, Benedito aponta o lugar em que deve ser buscada a originalidade da peça: "no norte, na minha saudosa Bahia. Os nossos avós, quando vieram da África, construíram as primeiras palhoças na Bahia, e foram delas que saíram as primeiras mulatas e negras brasileiras". Ao que se segue uma "baiana", cantando uma música com letra cheia de dengues, no mesmo estilo das músicas compostas por Ari Barroso, em especial para Carmem Miranda, nos anos 30. ${ }^{9}$ Em apoio a esta cena, canta-se "Cristo nasceu na Bahia", composição de Sebastião Cirino e Duque, que se tornaria, a partir de então, um clássico da música popular:

"Dizem que Cristo nasceu em Belém

A história se enganou

Cristo nasceu na Bahia, meu bem

E o baiano criou

A Bahia tem vatapá

A Bahia tem caruru

Moqueca e arroz de aussá

Laranja, manga e caju

Cristo nasceu na Bahia, meu bem

Isto sempre hei de crer

Bahia é terra santa, também

Baiano santo há de ser."

Estudos Afro-Asiáticos, Ano 23, no 1, 2001, pp. 68-83 
Patrício nota, então, que não conhecia esta naturalidade de Cristo, observando com entusiasmo: "sim senhor! Não conhecia essa preciosidade! Também, nascido e criado em São Paulo!”. Ao que Benedito acrescenta: "pudera, vivendo quase no meio estrangeiro, não tiveste tempo nem ocasião de conhecer o que deverias!”. Em seguida, canta uma modinha, "à nossa alma, à sensibilidade da nossa raça!", para que Patrício não a confunda com "romanzas amacarronadas". Nota-se, então, que os dois personagens principais simbolizam dois brasis diferentes. $\mathrm{O}$ baiano Benedito, não por acaso tendo o nome do santo de grande popularidade entre a comunidade negra, é visto como verdadeira reserva de uma cultura negra apontada como autêntica, e fonte da mais pura brasilidade. Parecia, aqui, consolidada a associação — tão comum ainda nos dias de hoje — da Bahia com este imaginário da pureza da cultura negra. Por outro lado, o paulista Patrício desconhece as raízes do que é identificado como "cultura negra", sendo, por isto, caracterizado quase como estrangeiro, em especial por viver em São Paut lo. ${ }^{11}$ A Bahia (por sinal, terra natal de De Chocolat) simbolizaria um "Brasil negro", enquanto São Paulo seria a "Europa no Brasil". No caso, é fácil notar em qual destas duas opções se localizaria a brasilidade verdadeira.

Além da boa convivência entre as raças, a brasilidade seria, também, marcada, na visão da peça, por sua associação com os negros. Uma vedete, descrita no texto como "cançonetista francesa numa luxuosa toilette, ornada de plumas", canta uma canção francesa que a identifica como "Mistinguett brasileira". ${ }^{12}$ Logo, para abrasileirar uma atriz francesa, De Chocolat não a faz cantar um samba ou usar roupas mais comuns no Brasil. A cor negra de sua pele é suficiente para lhe dar "a graça dos brasileiros". Os símbolos do que é "ser negro" também soam bastante familiares. Um casamento inter-racial é salvo devido à utilização de rezas especiais, pela esposa negra, para impedir que seu marido volte para Portugal. A modinha é apresentada como "refletindo toda a alma sentimental e nostálgica da nossa raça". Uma preta africana canta um batuque. Um outro personagem exalta a feijoada.

Com tudo isto, a primeira reação de um leitor atual de Tudo Preto poderia ser a de pensar que a Companhia Negra de Revistas teria feito uma peça apelando apenas para o lado exótico da "gente da raça", com o intuito de fazer sucesso em uma sociedade preconceituosa. Contudo, este não parece ser o caminho mais frutífero para explicar as semelhanças entre a visão de raça e nação de uma peça que se autodenomina uma "revista negra", e o tratamento do

Estudos Afro-Asiáticos, Ano 23, no 1, 2001, pp. 69-83 
mesmo tema dado por autores que atualmente são rotulados como conservadores, tal como Gilberto Freyre. Afinal, o público do teatro de revista era bastante diversificado, e uma peça certamente não ficaria tanto tempo em cartaz fazendo sucesso apenas entre brancos que queriam rir do exotismo de uma manifestação negra. Além disto, o Teatro Rialto, onde era encenada a peça, não se caracterizava como território de elite. Pode-se, ainda, lembrar da contínua exaltação à peça por parte da imprensa negra paulistana. O fato é que, embora não seja possível afirmar nada em termos conclusivos, os poucos indícios sugerem que a peça foi aceita por amplos setores, não tendo desagradado particularmente à comunidade negra.

Talvez um crítico atual de Tudo Preto ressaltasse, ainda, algumas passagens sobre os negros que dificilmente seriam tranqüilamente aceitas em fins do século XX. Pode-se lembrar alguns momentos que chegam a constranger o leitor atual do texto da peça, devido ao seu gosto no mínimo duvidoso para os padrões posteriores. Um exemplo se dá quando Patrício e Benedito observam que uma peça representada apenas com atores negros daria grande lucro à Light, pois a iluminação teria de ser muito mais forte. Contudo, isto está ligado à dinâmica do teatro de revista, inteiramente inserida na cultura de massas. Por um lado, era necessário satisfazer, ao menos de passagem, espectadores menos propensos a uma aberta exaltação da "gente da raça". Por outro, a cena poderia apenas ressaltar a "escuridão" como peculiaridade dos negros, ainda que isso soe estranho atualmente. De qualquer forma, não se pode correr o risco do anacronismo e postular, a priori, que tal passagem de Tudo Preto soasse mal para os simpatizantes dos negros. Enfim, deve-se sempre ter em mente o caráter ambíguo destas peças, já que, longe de ser "teatro de tese", o teatro de revista visava dar aos temas um tratamento que pudesse satisfazer o maior número possível de gostos. Possivelmente, esta cena seja mais um exemplo desta característica.

Por outro lado, o amplo sucesso de Tudo Preto poderia nos levar a fazer uma interpretação que seguisse por um caminho diverso: a de que esta idéia de "Brasil mestiço", hoje tida como mascaradora do racismo brasileiro, tenha, em um outro contexto histórico, sido popular entre os negros, incluindo os que militavam abertamente contra o racismo. Em um período próximo da ampla difusão de idéias como branqueamento e racismo científico, e no qual a imprensa negra paulista noticiava seguidamente os espancamentos sofridos por não-brancos nos Estados Unidos e denunciava a

Estudos Afro-Asiáticos, Ano 23, no 1, 2001, pp. 70-83 
violência das relações raciais nos EUA, ${ }^{13}$ a idéia de democracia racial como peculiaridade nacional não parece ter soado como desprezível, pelo menos para parte da comunidade negra. Tudo Preto é apenas um indício neste sentido, mas talvez seja interessante para se começar a considerar a hipótese de que negros tenham lutado por uma concepção mestiça de Brasil, na qual não haveria problemas raciais, e o conceito de brasilidade estaria intimamente associado com a "gente da raça". Isto indicaria que a idéia de democracia racial, ainda que possa ter na prática um efeito mascarador da violência das relações raciais no Brasil, teve vários sentidos no momento de sua formulação, longe de ter sido meramente um estratagema de grupos de elite com objetivos de dominação. No momento estudado, a idéia de "Brasil mestiço" poderia ser, em parte, uma reivindicação orgulhosa da contribuição do negro para a formação da nação. Vale lembrar, por exemplo, que a exaltação a Henrique Dias como fonte de orgulho negro não deixa de seguir uma tradição colonial, quando os regimentos negros de milícia se autodenominavam henriques, em referência ao personagem citado (Schwartz, 1999:414).

Vale a pena, ainda, ressaltar que em alguns momentos da peça se nota uma certa dissonância entre a proposta de identidade étnica e nacional de Tudo Preto, e a identidade nacional tal qual descrita por autores como Gilberto Freyre, que buscam, em um passado distante, a contribuição do negro para a cultura brasileira. Um exemplo está em um quadro da peça no qual aparece um almofadinha negro. Os almofadinhas eram um tipo freqüentemente ridicularizado no teatro de revista, em função de sua elegância afetada. Em Tudo Preto, o fato se repete (é descrito no texto como "ridículo e metido a rico"), mas De Chocolat faz questão de ressaltar que se trata de um almofadinha negro (o personagem não tem nome, mas é designado apenas como "preto elegante"), que utiliza muitas gírias em inglês e está acompanhado por black girls vestidas de calças e luvas. Aqui, é necessário levar em conta o fato de, na primeira cena, Patrício afirmar o objetivo da peça como sendo o de demonstrar que os negros não são apenas serviçais. Tendo-se em mente este propósito, declarado na primeira cena da peça, este personagem ganha um sentido claro: reivindicar para a raça negra não apenas as origens folclóricas de um caráter nacional, mas também o desfrute de uma urbanidade civilizada, mesmo que sob o risco da afetação (ainda que, dentro da ambigüidade que caracteriza o teatro de revista, esta cena pudesse ser lida como a comprovação de que os negros tendem a simplesmente imitar os brancos). Não obs-

Estudos Afro-Asiáticos, Ano 23, no 1, 2001, pp. 71-83 
tante tal apelo, os personagens negros do teatro de revista continuaram a ser malandros de morro, domésticas e outros personagens "típicos". Mas, não deixa de ser sugestivo que, em uma "peça negra", se tente mostrar que os negros possam representar não apenas as raízes da nacionalidade, como também o seu presente.

Outro dado a ser ressaltado em Tudo Pretoé a escolha realizada pelo autor entre as manifestaçóes culturais negras que poderiam ser apresentadas em um palco de teatro de revista, perante um público amplo. Afinal, são privilegiados alguns símbolos específicos da cultura negra, como a Mãe Negra, alguns gêneros musicais, a mistura religiosa e a feijoada, enquanto outros, por exemplo a capoeira, são esquecidos. Muito se escreveu visando explicar, através de uma genérica "valorização da mestiçagem", ocorrida entre os anos 1920 e 1930, a utilização de produtos da "cultura negra" ou da "cultura popular urbana" na constituição de uma idéia mestiça de caráter nacional (um exemplo recente de grande repercussão é Vianna, 1995). Contudo, noções como "cultura negra" ou "cultura popular urbana" não podem ser tratadas como uma totalidade, visto que comportam um grande número de manifestações culturais, algumas das quais foram elevadas ao status de símbolo nacional, enquanto outras não tiveram a mesma sorte. A idéia de "ser negro" em Tudo Preto não parece associada a manifestações como a capoeira, e seu resgate do passado não inclui, de forma alguma, o carnaval popular. Os caminhos que levaram à adoção de alguns símbolos "mestiços" como parte de um "caráter nacional", enquanto outros eram pouco ou nada celebrados, são um tema que ainda requer investigação. Contudo, é irresistível a suspeita de que, ao ser exaltada como "cultura nacional", essa "cultura negra" teria sido depurada de suas manifestações, que poderiam soar como ameaçadoras a um público menos propenso a aceitar a idéia de que os negros simbolizariam o caráter nacional. Assim, esta "cultura negra urbana" teria sido previamente polida, a fim de se tornar mais tranquilizadora. De qualquer forma, vale registrar que explicações centradas em uma ampla e genérica "valorização da cultura negra", a fim de entender a ascensão do samba ou da mulata ao papel de símbolos nacionais, nunca poderão dar conta de explicar os métodos que levaram à seleção de uma "cultura negra urbana" específica como "cultura nacional". Por que o samba antes que a capoeira? Por que o malandro sambista antes que o malandro de navalha? São questões ainda praticamente virgens na pesquisa acadêmica.

Estudos Afro-Asiáticos, Ano 23, no 1, 2001, pp. 72-83 
Outro dado interessante é a apoteose da revista. As apoteoses, nas convenções do teatro de revista, funcionavam como um grand finale para as peças, quando a companhia inteira voltava ao palco para dançar ao som de alguma música, geralmente em exaltação a algum tema. E a apoteose de Tudo Preto, lamentavelmente não descrita no texto da peça, denomina-se "Mãe Negra". O mais provável é que a peça reivindicasse o reconhecimento da contribuição da raça negra na formação do Brasil, simbolizada na Mãe Negra. Hoje em dia, tal símbolo remete diretamente a Gilberto Freyre, portanto à idéia de uma ideologia branca. Mas, no contexto da década de 1920, esta figura assume outra conotação: tanto no Rio de Janeiro como em São Paulo, grupos negros lutavam para conseguir erigir monumentos em homenagem à Mãe Negra, assunto amplamente comentado na Capital Federal quando da encenação de Tudo Preto. A idéia havia sido lançada por Cândido Campos, no jornal $A$ Notícia, alguns meses antes, e era intensamente debatida na imprensa, sendo a construção do monumento defendida por cronistas como Benjamin Costallat, em uma passagem que inclusive ajuda a iluminar a tradicional presença dos negros nos palcos da revista carioca antes da encenação de Tudo Preto: "Não devemos apenas querer bem ao negro, nem das negras fazer estrelas de teatro. $\mathrm{O}$ negro merece que lhe levantemos o monumento da gratidão brasileira" (A Notícia, 24/4/1926).

Esses movimentos acabaram por tornar-se bandeiras aglutinadoras de grupos negros do período. Com isto, é possível imaginar que a apoteose pudesse ser fundamentalmente uma tomada de posição política a favor do movimento pela construção do monumento à Mãe Negra, mas sem deixar de lado a exaltação a uma brasilidade fortemente associada à cultura negra.

Como já foi mencionado, as críticas não apontam uma grande quebra no quadro normal do teatro de revista carioca devido a Tudo Preto. Musicalmente, a peça agradou em cheio, tendo lançado um dos maiores clássicos da década, a citada "Cristo nasceu na Bahia”. Segundo Hermano Vianna (1995:25), esta peça teria originado a vontade de Gilberto Freyre de conhecer melhor a música de Pixinguinha. Em geral, a imprensa da época reteve também a singularidade do fato de uma apresentação exclusivamente negra em um palco. Isto apontava, também, um triunfo do próprio esquema publicitário da Companhia Negra de Revistas, que freqüentemente ressaltou seu ineditismo nos anúncios de jornal. Dois dias antes da estréia, os jornais da Capital Federal traziam um anúncio da Companhia que conclamava o público a assistir "o

Estudos Afro-Asiáticos, Ano 23, no 1, 2001, pp. 73-83 
mais original dos espetáculos até hoje visto no Brasil: Companhia Negra de Revistas, no Teatro Rialto". O texto fala, ainda, em "grande procura por bilhetes de entrada". Na véspera da estréia, o anúncio é mais detalhado, falando em " 32 figuras de elenco! Uma bailarina clássica! Uma excêntrica! 18 Nigrolemas Girls!”. A Companhia Negra de Revistas não pareceu desprezar nenhuma das formas de atrair o público. Entre as estratégias, pode-se notar a exaltação das peculiaridades da "gente da raça" e da brasilidade, assim como o enquadramento de Tudo Preto em um quadro no qual o elemento exótico tinha forte apelo. Neste sentido, a valorização da cultura negra em parte era legitimada pelo fenômeno análogo que ocorria em Paris, e que fazia sucesso no Brasil naquele mesmo momento através de companhias de revista francesas. Este fenômeno em território nacional, certamente teve uma importância muito maior que a de uma moda passageira, modificando toda a auto-imagem do Brasil. Aqui, nota-se uma importante peculiaridade do desenvolvimento do debate sobre mestiçagem e identidade nacional no âmbito da cultura de massas: a recorrente referência à França, neste caso visando emprestar o prestígio da companhia francesa Ba-Ta-Clan ao empreendimento da Companhia Negra de Revistas.

E não há dúvidas de que, tanto a Companhia Negra de Revistas, quanto grande parte do público estava ciente deste sucesso das produções culturais vistas como negras na Paris do pós-guerra, e o próprio teatro de revista oferece exemplos neste sentido. Outro deles seria através de uma companhia sobre a qual ainda se sabe muito pouco, a Companhia Mulata Brasileira. Em uma entrevista com uma de suas estrelas, Jaci Aimoré (definida pelo repórter como "mulatinha dengosa, de passo miudinho e muito pernóstica"), fica ainda mais claro a consciência deste contexto entre os artistas. A artista declara ao repórter sua vontade de "ir para fora". Convidada a especificar melhor este seu desejo, Jaci Aimoré afirma: "para o estrangeiro, para a Argentina, para a Europa. Dizem que por lá gostam muito de mulatas, por isso quero ver se é verdade" (O Globo, 17/12/1930). Assim, este grupo de negros aqui estudado, provavelmente estava muito consciente do que fazia ao buscar agenciar sua presença como núcleo da identidade nacional em um momento em que parecia se abrir esta possibilidade.

É absolutamente indispensável, contudo, notar que, ao se apontar a relação entre o sucesso de manifestações culturais negras em Paris e uma maior abertura a manifestações vistas como similares em território nacional, não se pretende reafirmar a incontavel-

Estudos Afro-Asiáticos, Ano 23, no 1, 2001, pp. 74-83 
Negros Contando (e Fazendo) sua História...

mente repetida tendência atávica do Brasil para a mera cópia do estrangeiro. Afinal, a(s) cultura(s) negra $(s)$ era $(m)$ valorizada $(s)$ em Paris como parte de um amplo contexto em que culturas exóticas obtinham grande sucesso na capital francesa. Produções culturais russas obtinham talvez ainda mais sucesso, bastando lembrar da notoriedade de Stravinsky, Diaghilev ou Nijinsky, no mesmo período. O Oriente Médio e o Extremo Oriente também tinham seu lugar neste processo, assim como o tango argentino. Portanto, pode-se perceber que esta atmosfera parisiense foi utilizada de modo bastante seletivo no Brasil, especialmente no que tange às estratégias de reconhecimento por parte de grupos negros, que a utilizaram como importante componente em sua luta por cidadania.

Em território paulista, a trajetória da Companhia Negra de Revistas parece ter tido outros sentidos. Na verdade, a Companhia chegou em fins de outubro já dividida — possivelmente por divergências pessoais entre seus membros - em duas: a Companhia Negra de Revistas e a Ba-Ta-Clan Preta, ${ }^{14}$ tendo ambas visitado São Paulo entre outubro e novembro de 1926. A Companhia Negra de Revistas não recebeu maior destaque da grande imprensa, ainda que Tudo Preto tenha sido elogiada: "quer pela concorrência que tiveram as duas sessōes, quer pelos aplausos com que foram recebidos vários números da peça, resultou em mais um animador sucesso". ${ }^{15} \mathrm{Na}$ verdade, esta era uma Companhia Negra de Revistas bastante desfalcada, pois a maior parte dos nomes de peso da companhia ficou com a Ba-Ta-Clan Preta, inclusive Pixinguinha e De Chocolat. O grande sucesso estampado nos cartazes da Companhia era o ainda jovem Grande Otelo. A companhia se apresentou no Teatro Apolo, no Teatro Mafalda (no Brás) e no Cassino Antártica, despedindo-se de São Paulo no dia 10 de novembro.

A 11 de novembro estreava no Teatro Santa Helena a Companhia Ba-Ta-Clan Preta, precedida de amplo esquema promocional. Dez dias antes, $O$ Estado de São Paulo já anunciava a estréia, fato repetido no dia 7, com um grande anúncio da peça Na Penumbra, anunciando a presença de músicos famosos como Pixinguinha e Bonfiglio de Oliveira e " 12 mulheres de ébano, 12 mulheres de azeviche", definindo-se como uma "revista negra". No dia 9, o crítico teatral d' $O$ Estado de São Paulo afirmava que "têm sido bastante procuradas as entradas para o Santa Helena". Na véspera da peça, a publicidade da Ba-Ta-Clan Preta anunciava "30 mulheres

Estudos Afro-Asiáticos, Ano 23, no 1, 2001, pp. 75-83 
de ébano e uma jazz-band de azeviche". No dia da estréia o crítico teatral do mesmo jornal comentava a expectativa da apresentação, e a publicidade da empresa mostrava um enorme anúncio com um desenho da estrela Deo Costa nua, envolta em lençóis negros, com a legenda "A Vênus de Jambo". O anúncio ainda prometia uma jazz-band, dois trompetes, além de trombone, saxofone, piano e bateria. No dia seguinte, o comentário do crítico teatral d'O Estado de São Paulo dá grande destaque à peça, elogiando principalmente os músicos e atores, criticando porém a excessiva imitação parisiense e cobrando mais originalidade. Aparentemente, a Companhia seguiu o conselho, visto que já no dia seguinte o mesmo cronista elogiava as mudanças feitas na peça, que teria ficado "mais leve e interessante", graças à intensificação dos números de "música característica e danças típicas". Com o tempo, a Companhia deixa de ser notícia. Talvez para recuperar o sucesso, volta a Tudo Preto, depois faz uma síntese das duas peças, denominada $A$ Revista das Revistas. ${ }^{16}$ A despedida da Companhia, no dia 22 de novembro, recebe um destaque mínimo.

A evolução do posicionamento da crítica teatral e dos anúncios publicitários da Companhia indica um sentido claro. Aparentemente, a Ba-Ta-Clan Preta pensava seguir a mesma receita de sucesso utilizada no Rio de Janeiro, misturando exaltação à "gente da raça” e associação a uma modernidade cosmopolita, que não deixava de fazer seu apelo ao exótico. Porém, o público da capital paulista, em boa parte marcado por uma outra forma de exaltação ao "nacional" e ao "popular", voltada para o nativismo sertanejo (Sevcenko, 1992:236-57), preferiu o lado "típico" da Ba-Ta-Clan Preta. E mesmo assim, parece ter sido, antes, um modismo que rapidamente perdeu fôlego. O mais provável é que esta exaltação da nacionalidade brasileira, fundada em manifestações negras não apenas rurais, mas também urbanas, não tenha encontrado solo fértil na capital paulista, onde os bandeirantes eram exaltados como glórias nacionais. Certamente, este símbolo estava relacionado a outros tipos de associações com o passado. Sevcenko (1992) enfatiza, nesta exaltação ao bandeirante, uma forma de distinção das elites tradicionais paulistas frente à desagregação de sua autoridade, causada pelos imigrantes e pelo crescimento urbano e industrial. Já Bresciani (1999), tende a enfatizar a importância do bandeirante como reorganizador da identidade paulista, após a perplexidade causada pela explosão populacional de São Paulo no final do século XIX e início do XX.

Estudos Afro-Asiáticos, Ano 23, no 1, 2001, pp. 76-83 
Negros Contando (e Fazendo) sua História...

Para os objetivos deste texto, é suficiente notar que, tendo em vista o debate transcorrido em São Paulo, pode-se supor que parte significativa do público não tivesse sido receptivo à forma utilizada pelas duas companhias cariocas para exaltar a brasilidade. Pode-se imaginar a decepção de paulistas, que eventualmente tenham ido assistir a uma companhia de teatro formada por negros com a expectativa de ver um espetáculo "típico", e encontrando, na verdade, negros tocando música popular urbana e, muitas vezes, estrangeira.

A já citada Companhia Mulata de Revistas parece sintetizar admiravelmente a argumentação aqui desenvolvida. Formada em São Paulo, mas tendo excursionado ao Rio de Janeiro, a companhia apostava largamente no imaginário folclórico-regionalista para vender seu produto. No jornal carioca $A$ Noite, de 15/12/30 (quatro dias antes da estréia da companhia no Rio de Janeiro), via-se um anúncio da peça Batuque, Cateretê e Maxixe, de meia página, com um desenho representado uma festa escrava, em um ambiente rural, e o título "Entra Macacada!". Aqui, é desnecessário insistir muito na diferença em relação aos anúncios da Companhia Negra de Revistas, que sublinhavam sua associação com uma modernidade cosmopolita, falando em jazz bands e vedetes de pouca roupa. Não se pode, contudo, simplificar esta questão, caracterizando paulistas e fluminenses como duas totalidades monolíticas que esperam de "seus" negros coisas totalmente diferentes. Esta crítica de Batuque, Cateretê e Maxixe, feita por um crítico carioca, ancorada em uma comparação com Tudo Preto, demonstra definitivamente a inviabilidade de realizar uma inflexível clivagem entre a atmosfera cultural no Rio de Janeiro e em São Paulo. A crítica, afinal, poderia ter sido escrita pelo mais ardoroso regionalista sertanejo paulista:

Muito interessante, muito superior ao que fora dado esperar, esteve a estréia da Companhia Mulata Brasileira ontem, no Teatro República. Pode mesmo ficar certo o público freqüentador de teatros de que esta exibição de agora é coisa muito diferente da que, há anos, foi feita no Rialto. A de anos passados teve de fracassar, e esta, a de ontem, é justo que vá avante. O conjunto de agora está bem orientado; não é levado a ridículas imitaçôes de coisas estrangeiras e incompatíveis com o característico da Companhia, ao contrário, explora aspectos regionais, episódios e música brasileira, quase sempre do interior do país, e daí o estar bem à vontade, no desenrolar numeroso de quadros, cenas e cortinas. ( $O$ Globo, 20/12/1930).

Estudos Afro-Asiáticos, Ano 23, no 1, 2001, pp. 77-83 
Neste texto, o negro claramente tem um lugar definido na sociedade: o de representar uma brasilidade folclórica; a modernidade cosmopolita é, aqui, verdadeiramente "incompatível com o característico da companhia”. A partir desta afirmação, pressupõe-se que o papel do negro é o de reserva folclórica, inatingível pela modernidade, cujas vantagens parecem ser reservadas aos brancos. Não por acaso, nota-se uma crítica do cronista à Companhia Negra de Revistas quatro anos após sua atuação. O negro, aqui, aparece como mais um caso típico de "beleza do morto". ${ }^{17}$

Por outro lado, para o movimento negro paulistano, organizado em torno de periódicos e associações, a Companhia Negra de Revistas era, já no momento de sua estréia na Capital Federal, algo a ser ressaltado com grande destaque:

Nossos parabéns!...

Felizmente, o nosso progresso nestes últimos tempos é um fato que diariamente vai-se multiplicando, apesar dos pesares.

Nas rodas esportivas já possuímos valorosos competidores e em todas as atividades humanas: ciências, artes, disciplinas várias e letras; o nosso teatro ligeiro está de parabéns, um fato interessante que de há muito era esperado, hoje nos apresenta para concretizar a nossa crescente evolução: fundou-se, lá na capital do nosso país, uma Companhia Negra de Revistas, graças ao conhecido e prestimoso homem de teatro, o grande cenógrafo Jaime Silva e demais pessoas que emprestaram seu auxílio e ao aplaudido De Chocolat, conhecido em todos os palcos da Europa, que escrevera propositadamente a revista de estréia, desse conjunto 'Tudo Preto' que tem conquistado inúmeras palmas do povo carioca, e musicada pelo Sr. Cirino. [...]

É para todos nós, este acontecimento teatral, mais um passo firme e vitorioso ao templo do progresso, na evolução do nosso país. Portanto, seria uma injustiça de nossa parte, deixar na obscuridade esse fato, que vai portanto concorrer para o reerguimento do teatro nacional (Clarim d'Alvorada, 22/8/1926).

A chegada da Companhia Negra de Revistas a São Paulo seria um evento amplamente comentado na capital paulista. A Companhia Negra de Revistas estreou ainda em outubro no Teatro Apolo. O Clarim d'Alvorada não deixou de registrar o evento:

Nós, paulistanos e paulistas, brasileiros sensatos, hoje, mais que nunca estamos satisfeitos. Um fato importantíssimo vem concorrer com a desejada ansiedade de longos meses em expectativa, é o da estréia da Cia. Negra de Revistas, no Apolo.

Para lá nos dirigimos, aplaudimos com veemência, entusiasmo os nossos patrícios, nesse espetáculo inédito e de tantas excentricidades; os nossos artistas foram merecedores, portanto é de justiça mais uma vez expressar

Estudos Afro-Asiáticos, Ano 23, no 1, 2001, pp. 78-83 
Negros Contando (e Fazendo) sua História...

\begin{abstract}
de coração os nossos francos aplausos a Jaime Silva, o grande organizador desse conjunto, e o artista patrício De Chocolat.

Temos, pois, a nossa consagração e portanto é mister labutarmos sempre com ânimo forte para que se alimente o nosso progresso.

A época é nossa, conforme afirmações inúmeras; essa novidade teatral surgiu na Cidade-Luz - Paris, com Josephine Baker, hoje entre nós brasileiros está se celebrizando; todos nós devemos, de bom grado, ir aplaudir os patrícios que com ardor e boa vontade estão labutando encorajosamente para o complemento de nossas glórias" (Clarim d'Alvorada, 24/10/1926, ênfases minhas).
\end{abstract}

Para a militância negra paulistana, o evento se recobria de um sentido claro: o de demonstrar a possibilidade do negro de alcançar o sucesso em atividades diversas. Pode-se notar, ainda, em especial nos trechos grifados, a presença, também aqui, da França como legitimadora da iniciativa da companhia. O principal é notar que, em um momento no qual a elite paulista reescrevia a história de São Paulo, falando de um passado distante em que apenas quatrocentôes e índios mereciam papel de destaque, a associação entre os "patrícios" e a brasilidade (e também a crítica às "romanzas amacarronadas") promovida por Tudo Preto, deve ter soado como música aos ouvidos da militância. A passagem da Companhia Negra de Revistas por São Paulo marcou época no meio cultural negro paulistano, que pareceu se maravilhar com a qualidade da produção da Companhia. Por seu lado, seus membros, segundo o militante José Correia Leite, teriam se deliciado com os bailes exclusivamente negros da capital paulista. ${ }^{18}$ Não há pistas que indiquem que a Companhia tenha sido encarada como um fenômeno com tal singularidade na Capital Federal, onde, de resto, atividades culturais negras eram difundidas diariamente, com grande sucesso, no âmbito do entretenimento massificado, além de artistas presentes em grupos não exclusivamente negros. Em São Paulo, onde a cultura de massas era permeada por um debate marcado pela associação da identidade paulista com outros símbolos, é possível indicar que a Companhia Negra de Revistas tenha sido encarada de outra forma, e seu caráter "negro" tenha chamado mais a atenção.

Esta recepção diferenciada permite levantar uma hipótese: a de que a exaltação da cultura negra como nacional possa ter ligação com o sensível aumento da difusão de produtos culturais como o samba, pelos caminhos do entretenimento massificado (peças teatrais, discos, rádio, publicaçóes popularizando a música popular etc). Ganhando mais visibilidade através dos meios de difusão disponíveis pela massificação cultural, a cultura negra teria tido a

Estudos Afro-Asiáticos, Ano 23, no 1, 2001, pp. 79-83 
oportunidade de conquistar, paulatinamente, uma maior audiência e consolidar-se como cultura nacional. Pode-se notar que o desenvolvimento da cultura de massas, no Brasil, ocorre paralelamente à valorização das "raízes populares da nacionalidade", ambas ganhando mais visibilidade nos anos do pós-guerra para se consolidarem de forma generalizada entre as décadas de 1930 e 1940. É, ainda, uma mera hipótese a ser investigada, mas é possível, a partir dela, inserir uma nova e importante dimensão no debate sobre a identidade nacional, e sugerir uma explicação para a grande importância da cultura negra urbana na definição da nacionalidade.

De qualquer forma, a experiência da Ba-Ta-Clan Preta ajuda a iluminar alguns elementos deste período de discussões sobre identidade nacional, como a relevância das peculiaridades regionais, a importância do lado exótico dos elementos "populares" exaltados para uma parcela do público, assim como o caráter central da exaltação da "gente da raça" para outros segmentos, e a forte presença do fenômeno da massificação cultural neste debate, entre outros dados presentes. O debate sobre a identidade nacional, na experiência aqui estudada, recobre-se de vários sentidos e aparece como amplamente presente na sociedade urbana brasileira do período.

Como já explicitado anteriormente, Tudo Preto e a experiência da Companhia Negra de Revistas estão ausentes da história cultural do Brasil, assim como dos estudos sobre a formação de identidades. Uma explicação possível é o pouco espaço que historiadores e cientistas sociais têm dedicado à massificação cultural, o que acaba gerando a insuficiência de trabalhos sobre o teatro de revista. Por outro lado, a preferência pela história intelectual, como ferramenta para se compreender a formação da identidade nacional, não deixa de revelar uma concepção de que o público mais amplo não teria tido um papel importante no processo. Chega a ser curioso notar que um dos únicos textos que mencionaram a Companhia Negra de Revistas tenha elaborado o seguinte comentário:

Só não se falou no autor ou nos autores no texto, sabendo-se que De Chocolat havia criado alguma coisa, mas escrever não era a sua especialidade. É provável que por ser branco (Luís Peixoto? Carlos Bittencourt? Marques Porto? Qual deles?), o autor tenha preferido o anonimato (Cabral, 1997:108).

Estudos Afro-Asiáticos, Ano 23, no 1, 2001, pp. 80-83 
O que é impossível deixar de notar é que Sérgio Cabral não tenha sequer cogitado a idéia de que De Chocolat poderia ter efetivamente escrito Tudo Preto, ainda que todos os cartazes promocionais da Companhia e o texto da peça tragam indicação de autoria. Parece ter, mesmo sem nenhum indício, a certeza de que outra pessoa teria escrito o texto. Por isto, acaba cogitando três dos principais escritores do teatro de revista do período, ainda que o estilo de Tudo Preto nada tenha a ver com o estilo dos autores citados. A pergunta que fica é: seria um negro, estranho aos grupos intelectuais de nome, incapaz de debater a questão do caráter nacional e das identidades raciais?

Ainda hoje há uma tendência a concordar com esta idéia, não tendo sido ainda cogitada a possibilidade de que grupos mais amplos da sociedade possam ter participado do processo de discussão destes temas. O que Tudo Preto e a Companhia Negra de Revistas sugerem, é que talvez valha a pena pensar de outra maneira, sublinhando de forma mais enfática as experiências cotidianas destes outros grupos, e sua relação com o desenvolvimento do debate sobre a formação de identidades sociais e culturais.

\section{Notas}

1. Muitas pessoas debateram este texto em sua fase de preparação, e agradeço a todas elas, assim como ao meu orientador, Robert W. Slenes, e minha amiga Micol Seigel, a quem esta pesquisa muito deve. Não se pode deixar de mencionar ainda a FAPESP, agência financiadora de minha pesquisa de doutorado, da qual este artigo é parte.

2. Em 1925, uma entrada no que era então o maior templo do teatro de revista carioca, o Teatro São José, na Praça Tiradentes, variava de 1,5 mil-réis (geral) a 25 mil-réis (frisas e camarotes). Ver os arquivos da Empresa Pascoal Segreto, que era a dona do teatro nesse período (Biblioteca Nacional — Divisão de Música Popular).

3. Ver, ainda, um trabalho sobre outro período, em Mencarelli (1999).

4. Vale notar, ainda, a presença de um "bailado argentino", certamente relacionado ao sucesso do tango em Paris.

5. Sobre este aspecto do imaginário circense, ver Duarte (1995, esp. cap. 3.2).

6. Situação semelhante na capital paulista foi estudada por Sevcenko (1992, cap. 4).

7. Ver o Clarim d'Alvorada, 22/8/1926, 24/10/1926 e 14/11/1926.

8. Um exemplo é $O$ Estado de São Paulo, que aborda o tema por diversas vezes em novembro de 1926.

9. Estas composições "baianas" de Ari Barroso são tradicionalmente apontadas pela bibliografia como manifestações de uma faceta integradora do regime Vargas. Se assim for, a presença desta composição, já em 1926 (anterior, portanto, a Vargas e Ari Barroso), apóia a idéia de que esta "brasilidade" imposta por Vargas teria, no máximo, se aproveitado de um fenômeno da música popular já existente. Isto reforçaria a idéia

Estudos Afro-Asiáticos, Ano 23, no 1, 2001, pp. 81-83 


\section{Tiago de Melo Gomes}

de que a concepção "mestiça" do Brasil, muitas vezes apontada como mera imposição das elites, pode ter sido, em boa parte, influenciada pela cultura de massas.

10. Duque, o provável autor da letra, era um bailarino que havia obtido grande sucesso dançando maxixe em Paris, e certamente deveria conhecer as possibilidades comerciais desta valorização, um tanto exótica, da cultura negra.

11. Não por acaso, há referência às "romanzas amacarronadas": o imigrante europeu é, assim, associado a uma cultura alienígena, enquanto o negro simboliza uma cultura nacional autêntica.

12. Mistinguett era a principal estrela da companhia francesa Ba-Ta-Clan.

13. Neste caso, chama a atenção o recorrente uso da palavra "ódio" para definir as relações raciais nos EUA: Getulino, 21/10/1923 e 23/11/1924, Clarim d'Alvorada, 14/11/1926 e 2/12/1928; Progresso, 9/7/1928, 13/1/1929, 24/2/1929, 23/6/1929, $31 / 8 / 1929$ e 26/9/1929.

14. Note-se, aqui, a contínua referência à França: esta metade da companhia se apresenta como uma versão "preta" da citada companhia francesa.

15. O Estado de São Paulo, 4/11/1926. O escasso espaço dedicado à companhia na grande imprensa leva à pergunta: o que pensaria a platéia paulista do citado quadro de Tudo Preto em que São Paulo era caracterizada como território semi-estrangeiro? Seria esta uma explicação para seu pouco sucesso?

16. Note-se, mais uma vez, a influência da Ba-Ta-Clan: uma das peças encenadas por esta companhia em sua temporada brasileira, em 1926, denominava-se precisamente Revue des Revues.

17. O conceito de "beleza do morto" é de Certeau, Revel e Julia (1995).

18. Em suas memórias, José Correia Leite atribui o fim desta companhia ao fato de que os negros paulistanos teriam ficado transtornados pelas negras que nela trabalhavam, passando a oferecer todas as vantagens financeiras para que abandonassem a vida no teatro (Leite, 1992:50-1).

\section{Referências Bibliográficas}

BRESCIANI, Maria Stella Martins (1999). "Imagens de São Paulo: Estética e Cidadania”. In: A. Ferreira; T.R. de Luca, e Z. G. Iokoi (orgs.), Encontros com a História: Percursos Históricos e Historiográficos de São Paulo. São Paulo, Ed. Unesp, pp. 11-45.

CABRAL, Sérgio (1997). Pixinguinha: Vida e Obra. Rio de Janeiro, Lumiar.

CERTEAU, Michel de (1998). A Invenção do Cotidiano, Vol. I: artes de fazer. (3a ed.). Petrópolis, Vozes.

_ ; REVEL, Jacques e JULIA, Dominique (1995). “A Beleza do Morto”. In M. de Certeau, A Cultura no Plural. Campinas, Papirus, pp. 55-85.

DaMATTA, Roberto (1990). "Digressão: A Fábula das Três Raças, ou o Problema do Racismo à Brasileira”. In R. DaMatta, Relativizando: Uma Introdução à Antropologia Social (2a ed.). Rio de Janeiro, Rocco, pp. 58-85.

DANTAS, Beatriz Góis (1988). Vovó Nagô, Papai Branco: Usos e Abusos da África no Brasil. Rio de Janeiro, Graal.

DUARTE, Regina Horta (1995). Noites Circenses: Espetáculos de Teatro e Circo em Minas Gerais no Século XIX. Campinas, Ed. Unicamp.

Estudos Afro-Asiáticos, Ano 23, no 1, 2001, pp. 82-83 
Negros Contando (e Fazendo) sua História...

FRY, Peter (1982). "Feijoada e Soul Food: Notas sobre a Manipulação dos Símbolos Étnicos e Nacionais". In P. Fry, Para Inglês Ver: Identidade e Política na Cultura Brasileira. Rio de Janeiro, Zahar.

GOMES, Tiago de Melo (1998). Lenço no Pescoço: O Malandro no Teatro de Revista e na Música Popular. "Nacional”, "Popular" e Cultura de Massas nos anos 1920. Dissertação de Mestrado em História, Campinas, IFCH-Unicamp.

LEITE, José Correia (1992)....E Disse o Velho Militante. São Paulo, PMSP.

MENCARELLI, Fernando (1999). Cena Aberta: A Absolvição de um Bilontra e o Teatro de Revista de Artur Azevedo. Campinas, Ed. Unicamp-Cecult.

MOTA, Carlos Guilherme (1994). Ideologia da Cultura Brasileira (1933-1974). (8a ed.). São Paulo, Ática.

NUNES, Mário (1956). 40 Anos de Teatro. Rio de Janeiro, SNT, 4 vols.

ORTIZ, Renato (1994). Cultura Brasileira e Identidade Nacional. (5ª ed.). São Paulo, Brasiliense.

SCHWARCZ, Lilia Moritz (1995). "Complexo de Zé Carioca: Notas sobre uma Identidade Mestiça e Malandra”. Revista Brasileira de Ciências Sociais, no 29, pp. 49-63.

SCHWARTZ, Stuart B. (1999). "O Brasil Colonial, 1580-1750: As Grandes Lavouras e as Periferias”. In: L. Bethell (org.), História da América Latina, Vol. II: América Latina Colonial. São Paulo, FAG-Edusp, pp. 339-421.

SEVCENKO, Nicolau (1992). Orfeu Extático na Metrópole: São Paulo, Sociedade e Cultura nos Frementes Anos 20. São Paulo, Companhia das Letras.

SKIDMORE, Thomas (1989). Preto no Branco: Raça e Nacionalidade no Pensamento Brasileiro. (2a ed.). Rio de Janeiro, Paz e Terra.

VIANNA, Hermano (1995). O Mistério do Samba. Rio de Janeiro, Zahar/Ed. UFRJ.

Estudos Afro-Asiáticos, Ano 23, no 1, 2001, pp. 83-83 